\title{
Prefrontal Cortex and Dorsomedial Hypothalamus Mediate Food Reward-Induced Effects via npas2 and egr1 Expression in Rat
}

\author{
I. HERICHOVÁ ${ }^{1}$, K. HASÁKOVÁ ${ }^{1}$, D. LUKÁČOVÁ ${ }^{1}$, B. MRAVEC ${ }^{2,3}$, L. HORVÁTHOVÁ ${ }^{3}$, \\ D. KAVICKÁ ${ }^{1}$
}

${ }^{1}$ Department of Animal Physiology and Ethology, Faculty of Natural Sciences, Comenius University, Bratislava, Slovak Republic, ${ }^{2}$ Institute of Physiology, Faculty of Medicine, Comenius University, Bratislava, Slovak Republic, ${ }^{3}$ Institute of Experimental Endocrinology, Biomedical Research Center SAS, Slovak Academy of Sciences, Bratislava, Slovak Republic

Received March 10, 2017

Accepted October 25, 2017

\section{Summary}

The effects of food reward on circadian system function were investigated in the hypothalamic nuclei, prefrontal cortex and liver. Food rewards of small hedonic and caloric value were provided for 16 days $3 \mathrm{~h}$ after light phase onset to male Wistar rats. The daily pattern of locomotor activity was monitored. Gene expression profiling performed in the dorsomedial hypothalamus (DMH) and liver at the time of reward delivery indicated transcriptional factors egr1 and npas 2 as possible mediators of food reward effects. Candidate genes were measured in the suprachiasmatic nuclei (SCN), DMH, arcuate nucleus (ARC), prefrontal cortex (PFC) and liver along with per2 expression. A daily pattern in glycemia and per2 expression in the SCN was emphasized by food reward. The expression of egr 1 was rhythmic in the SCN, DMH, PFC and liver and food reward weakened or diminished this rhythm. The expression of npas 2 was rhythmic in all tissues except for the PFC where food reward induced rhythm in npas2 expression. Food reward induced npas2 and egr1 expression in the $\mathrm{DMH}$ at the time of reward delivery. We suppose that the DMH and PFC participate in the adjustment of the circadian system to utilize food reward-induced input via egr1 and npas2 expression.

\section{Key words}

npas2 • egr1 • DMH • Prefrontal cortex

\section{Corresponding author}

I. Herichová, Department of Animal Physiology and Ethology, Faculty of Natural Sciences, Comenius University Bratislava, Ilkovičová 6, 84215 Bratislava, Slovak Republic. E-mail: herichova@fns.uniba.sk

\section{Introduction}

A variety of interfering signals have influenced the activity of the circadian system in recent industrial society. In vulnerable individuals, impaired circadian system function can facilitate the development of pathologies. Recently this problem has attracted attention and strategies on how to achieve a proper synchronization of susceptible parts of the population are emerging. Although the role of melatonin, light control, sleep conditions and food intake in resynchronization is undisputable (Skene and Arendt 2006), there is still a problem with long-time acceptance of these treatments. Therefore, we focused on food reward as a possible alternative and/or supplemental tool for new and/or existing protocols.

The circadian system is hierarchically organized with the central oscillator localized in the hypothalamic suprachiasmatic nuclei (SCN) and peripheral oscillators localized in all other tissues. The molecular basis of the circadian oscillator relies on a feedback loop created by clock genes. There are three homologues of the per gene (per1, per2 and per3) and two homologues of the cry gene (cryl and cry2) in mammals. Their expression is induced via the E-box regulatory region by a heterodimer formed by the transcriptional factors CLOCK and BMAL1 (Damiola et al. 2000). Transcription factor NPAS2 (Neuronal PAS domain-containing protein 2) can functionally replace CLOCK (Reick et al. 2001).

A crucial role of clock genes in physiology is 
supported by experiments showing that bmall and clock deficiency is associated with metabolic disturbances, per 1 and per2 knockout is linked to changed cancer susceptibility and mutations in $c r y 1 / 2$ cause altered sleep pattern (Ko et al. 2006). The role of NPAS2 was investigated mainly in the forebrain. npas2-/-deficient mice exhibit modified behavior, react more rapidly to a changed light (L) dark (D) cycle than control and show restricted food-driven entrainment (Dudley et al. 2003).

The ways in which central and peripheral oscillators are synchronized differ (Damiola et al. 2000, Monošíková et al. 2007). The central oscillator is entrained mainly by the LD cycle and peripheral oscillators are very sensitive to food intake as a synchronizing cue (Damiola et al. 2000). Regulation of peripheral oscillators by food reward was investigated predominantly by evaluating changes in clock gene expression in the brain tissues. A rhythmic pattern in per 2 expression was reported in the basolateral amygdala, oval nucleus of the bed nucleus of the stria terminalis, central nucleus of the amygdala and dentate gyrus without an effect of food reward on per2 expression (Verwey et al. 2007). Food reward influences the expression of perl in the SCN but much more pronounced effects were observed in the striatum, cingulated cortex and piriform cortex (Mendoza et al. 2010).

A food reward can be interpreted by its hedonic as well as caloric value and there are many brain structures that can transmit this stimulus to the circadian system. The lateral hypothalamic nuclei and arcuate nucleus (ARC) are known to play a key role in food intake control (Lenard and Berthoud 2008). The dorsomedial hypothalamic nucleus (DMH) participates in food entrainment (Tahara and Shibata 2013), circadian regulation of arousal and wakefulness and responsiveness to the environmental cues important to animals (Schwartz and Roth 2008). The DMH is bidirectionally interconnected with the SCN (Morin 2013), which serves preferentially to transfer $\mathrm{SCN}$ regulation to the periphery but can also mediate DMH influence on the central oscillator. The prefrontal cortex (PFC) receives afferents from the thalamic nuclei and limbic structures; it is involved in many complex cognitive operations, in spatial and visual working memory, and is critical in executive functions involved in choosing behavioral strategy (Webb et al. 2015).

Food reward was shown to possess the capacity to synchronize the circadian system, although in the presence of the LD cycle its effect is overwhelmed by the light entrainment (Mendoza et al. 2010, Challet and Mendoza 2010). The influence of food reward on the circadian system probably depends on the hedonic value of the reward. In the case of a highly attractive reward or addictive drug, the mesocorticolimbic system is activated (Challet and Mendoza 2010). To eliminate the risk of mesocorticolimbic system overactivation and deregulation of energy homeostasis, a food reward of low hedonic and caloric value was chosen in our experiment.

The aim of the present study was to identify genes involved in food reward-induced processes in the SCN, DMH, ACR, PFC and liver after the selection of candidate genes by gene expression profiling. Food rewards of small hedonic and caloric value were applied during the light time. Candidate genes were analyzed along with per2 expression. To describe the function of the central oscillator a daily pattern of locomotor activity and glucose levels in plasma were monitored. The effect of food reward was compared to the effect of food restriction.

\section{Methods}

\section{Effect of food reward - Experiment 1}

Male Wistar rats $(\mathrm{n}=86)$ were obtained from VELAZ Praha (Czech Republic) at the age of 10-11 weeks. The animals were exposed to a 12:12 LD cycle with food and water ad libitum. After an acclimatization period the control group was exposed to the same regimen until the end of the experiment. The second group was provided with a food reward $(0.4 \mathrm{~g}$ piece of sponge biscuit) at ZT3 (ZT - Zeitgeber time, relativized time units; ZT0 corresponds to the beginning of the light phase of the LD regimen). The effect of the food reward was tested after 16 days of administration over a $24 \mathrm{~h}$ period in $4 \mathrm{~h}$ intervals. Samples of liver, blood and whole brains were taken at ZT2, ZT4, ZT6, ZT10, ZT14, ZT18 and ZT22 as described previously (Herichová et al. 2013).

Effect of food reward and food restriction - Experiment 2 Male Wistar rats $(\mathrm{n}=90)$ were obtained from Dobra Voda (Slovak Republic) at the age of 9-10 weeks. The animals were treated under the same conditions as in Experiment 1. The effect of food reward combined with food restriction was tested after 16 days. A food reward was provided at ZT3 together with standard pelleted food available for two hours (ZT3-ZT5). Sampling was performed as in Experiment 1. 
The experimental protocols were approved by the Ethical Committee for the Care and Use of Laboratory Animals at Comenius University Bratislava and the State Veterinary Authority. Experiments were carried out in accordance with the 86/609/EEC.

Glucose levels were measured in $10 \mu$ of plasma using commercial kits (GLU L1000, Erba Lachema s.r.o., Czech Republic).

The total RNA from tissues was isolated and gene expression was measured as described previously (Herichová et al. 2013). To identify genes involved in food reward response, the $\mathrm{RT}^{2}$ Profiler $^{\mathrm{TM}}$ PCR Array "Rat Circadian Rhythms" (PARN-153C) (Qiagen, Germany) was used. cDNA from the DMH and liver sampled at ZT4 (1 h after food reward) from Experiment 1 and cDNA from the liver sampled at ZT2 ( $1 \mathrm{~h}$ before food administration) from Experiment 2 were used to evaluate the effect of treatment on gene expression. We used samples taken at the time of the strongest behavioral response to the treatment in both experiments. Up- and downregulated genes were identified for each treatment (Table 1) and the expression of egrl and npas 2 was measured in all tissues along with that of per2.

Locomotor activity was monitored throughout Experiments 1 and 2 in home cages in the animal facility as described previously (Herichová et al. 2013).

\section{Statistical evaluation}

Daily profiles of gene expression and glucose were fitted into a cosine curve with a $24 \mathrm{~h}$ period and when experimental data significantly matched the cosine curve its parameters were calculated with $95 \%$ confidence limits. The goodness of fit ( $\mathrm{R}$ value correlation coefficient) of the approximated curve was estimated by analysis of variance (ANOVA) (Herichová et al. 2013, Monošíková et al. 2007). Time is expressed in relative units - Zeitgeber time $(\mathrm{ZT})$, where ZT0 is defined as the beginning of the light phase of the $24 \mathrm{~h}$ cycle. An unpaired t-test was used to test differences between two groups. Three groups were compared by one-way ANOVA. Data in graphs are presented as arithmetic mean and standard error of the mean (SEM).

\section{Results}

By day 16 of reward providing its consumption by animals is a well-trained habit. Food reward did not induce an anticipatory behavior as it was observed in food-restricted rats. However, we observed a significant increase in locomotor activity during the first hour after food reward administration $(\mathrm{P}<0.01$, $\mathrm{t}$-test). The averaged activity during the light part of the LD cycle did not differ significantly between the control and rewarded groups (t-test). Both the control and the rewarded group showed a typical daily pattern of locomotor activity with high levels during the dark phase. Food reward did not influence the amount of locomotor activity during the dark time (data not shown).

The averaged dark time values of plasma glucose levels showed an increase compared to light time concentrations ( $\mathrm{t}$-test, $\mathrm{P}<0.05$ ) in the control group, although the cosinor did not confirm a rhythmic pattern. Administration of food rewards over 16 days caused an increase in the robustness of the rhythmic pattern of glucose levels with the maximum during the dark part of the $24 \mathrm{~h}$ cycle (cosinor, Table 2 ).

Administration of food reward influenced the expression of eight genes with fold change $>2$ in the DMH. The most pronounced increase was observed in npas 2 expression (Table 1).

We observed an increase in egrl mRNA in the liver one hour after food reward (1.91-fold change). However, food reward did not show a strong impact on gene expression in the liver (Table 1).

Food restriction caused more than a twofold change in the expression of 19 genes in the liver. The most pronounced changes were observed in clock gene expression due to huge phase shifts induced by food restriction (Table 1).

Food reward was a much more efficient regulator of gene expression in the DMH than in the liver. Food reward combined with food restriction was a much more efficient input than food reward alone in the liver.

We observed a significant increase in npas 2 and egrl expression in the DMH of rats with access to food rewards over 16 days at ZT4 compared to the levels observed at ZT2 and ZT6 (Fig. 1A). The increase in npas 2 and egr 1 at ZT4 caused a diminishing of the daily rhythm in npas2 and egrl expression in the $\mathrm{DMH}$ (Fig. 1B, cosinor, Table 2). The expression of per2 showed a rhythmic pattern with a peak at the beginning of the dark part of the LD cycle in the DMH and goodness of fit of the rhythm numerically increased in the rewarded group of rats (Fig. 1B). 
Table 1. Effect of food reward and food restriction on gene expression in the DMH and liver of rats synchronized to a 12:12 LD cycle.

\begin{tabular}{cccc}
\hline & & $\begin{array}{c}\text { Effect of food reward on gene expression in the DMH } \\
\text { Fold increase compared to control }\end{array}$ & \\
\hline $\mathbf{2 . 4 0}$ & Npas2 & Neuronal PAS domain protein 2 & NM_001108214 \\
2.27 & Nkx2-5 & NK2 transcription factor related, locus 5 (Drosophila) & NM_053651 \\
1.41 & Timeless & Timeless homolog (Drosophila) & NM_031340 \\
1.29 & Opn3 & Opsin3 & NM_001191933 \\
1.21 & Hlf & Hepatic leukemia factor & XP_003752414 \\
\hline-2.15 & Atoh7 & Atonal homolog 7 (Drosophila) & NM_001170482 \\
-2.16 & Mtnr1a & Melatonin receptor 1A & NM_053676 \\
-2.71 & Prf1 & Perforin 1 (pore forming protein) & NM_017330 \\
-3.47 & Epo & Erythropoietin & NM_017001 \\
-5.40 & Tcfap2a & Transcription factor AP-2, alpha & NM_001107345 \\
\hline
\end{tabular}

Effect of food reward on gene expression in the liver

Fold increase compared to control

\begin{tabular}{|c|c|c|c|}
\hline 1.91 & Egr1 & Early growth response 1 & NM_012551 \\
\hline 1.82 & Bhlhe40 & Basic helix-loop-helix family, member e 40 & NP_003661 \\
\hline 1.46 & Nr1d1 & Nuclear receptor subfamily 1 , group D, member 1 & NM_145775 \\
\hline 1.35 & Creb3 & CAMP responsive element binding protein 3 & NM_001013092 \\
\hline 1.34 & Tcfap2a & Transcription factor AP-2, alpha & NM_001107345 \\
\hline \multicolumn{4}{|c|}{ Fold increase compared to control } \\
\hline-1.26 & Aanat & Arylalkylamine $\mathrm{N}$-acetyltransferase & NM_012818 \\
\hline-1.27 & Chrnb2 & Cholinergic receptor, nicotinic, beta 2 (neuronal) & NM_019297 \\
\hline-1.39 & Arntl2 & Aryl hydrocarbon receptor nuclear translocator-like 2 & NP_001234931 \\
\hline-1.61 & Epo & Erythropoietin & NM_017001 \\
\hline-1.68 & Prkarlb & Protein kinase, cAMP dependent regulatory, type I, beta & NM_001033679 \\
\hline \multicolumn{4}{|c|}{ Effect of food reward and food restriction on gene expression in the liver } \\
\hline \multicolumn{4}{|c|}{ Fold increase compared to control } \\
\hline 46.40 & Per3 & Period homolog 3 (Drosophila) & NM_023978 \\
\hline 29.05 & Dbp & D site of albumin promoter (albumin d-box) binding protein & NM_012543 \\
\hline 14.49 & Nr1d1 & Nuclear receptor subfamily 1 , group $\mathrm{D}$, member 1 & NM_145775 \\
\hline 9.86 & $\operatorname{Nr} 1 d 2$ & Nuclear receptor subfamily 1 , group D, member 2 & NM_147210 \\
\hline 6.74 & Per1 & Period homolog 3 (Drosophila) & NM_001034125 \\
\hline \multicolumn{4}{|c|}{ Fold increase compared to control } \\
\hline-2.21 & Ldha & Lactate dehydrogenase A & NM_017025 \\
\hline-2.27 & Stat5a & Signal transducer and activator of transcription $5 \mathrm{~A}$ & NM_017064 \\
\hline-2.58 & Srebf1 & Sterol regulatory element binding transcription factor 1 & NM_001276707 \\
\hline-5.19 & Prkacb & Protein kinase, cAMP dependent, catalytic, beta & NM_001077645 \\
\hline-19.49 & Arnt1 & Aryl hydrocarbon receptor nuclear translocator-like & NM_024362 \\
\hline
\end{tabular}

$1^{\text {st }}$ column - fold change in expression (treatment/control); $2^{\text {nd }}$ column - gene abbreviation; $3^{\text {rd }}$ column - gene name; $4^{\text {th }}$ column GenBank accession number. 

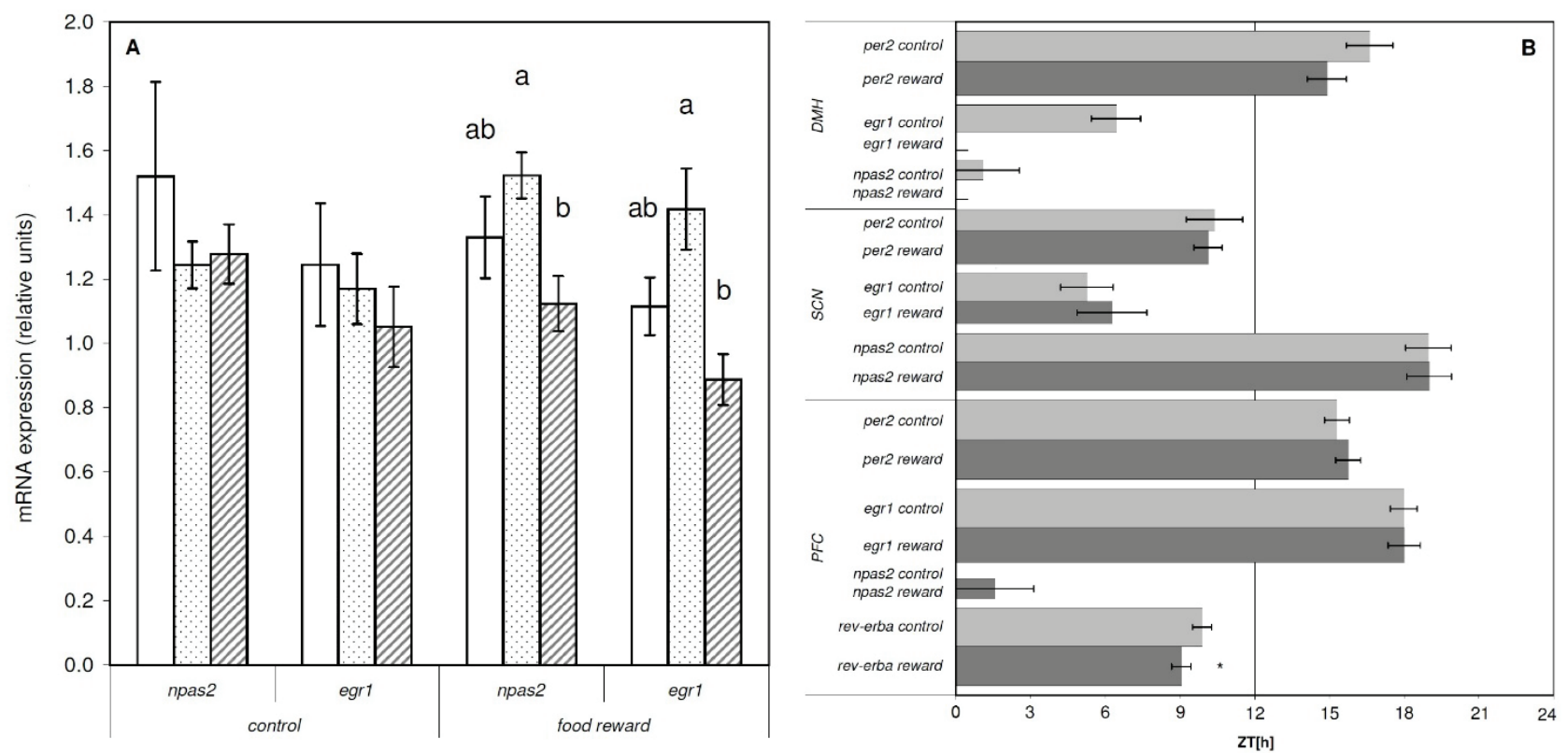

Fig. 1. Effect of food reward on (A) egr1 and npas2 expression in the DMH of rats synchronized to a $12: 12$ LD cycle ( $n=5-6)$. Food rewards were provided over 16 days $3 \mathrm{~h}$ after the beginning of the LD cycle (ZT3). White columns - ZT2; dotted columns - ZT4 (1 h after food reward delivery); cross-hatched columns - ZT6. The effect of food reward at ZT4 was compared to levels at ZT2 and ZT6. Columns with different alphabetical labels are significantly different (ANOVA). (B) Acrophases of egr1, npas2, rev-erba and per2 expression in the suprachiasmatic (SCN), arcuate (ARC) and dorsomedial (DMH) hypothalamic nuclei and prefrontal cortex (PFC) of control (gray columns) and rewarded (dark gray columns) rats $(n=5-6)$. Timescale is given in Zeitgeber time. The thickness of the columns corresponds to the goodness of fit (Table 2 ). $* \mathrm{P}<0.05$ t-test comparison of acrophases.

The expression of per2 in the SCN of the control group showed an expected pattern and food reward numerically increased goodness of fit of rhythmic per2 expression (Fig. 1B, cosinor, Table 2). The expression of egrl in the SCN showed a significant rhythm with a peak in the middle of the light phase (Fig. 1B, cosinor, Table 2), and food reward caused a numerical decrease in the goodness of fit of egr 1 rhythmic expression. npas 2 exerted a significant daily rhythm in the SCN with the maximum in the middle of the dark part of the LD cycle in both groups.

The expression of per2, npas 2 and egr 1 did not show changes in response to food reward in the ARC (cosinor, Table 2).

The expression of per2, npas 2 and egrl in the liver of the control group showed a rhythmic pattern and food reward caused a diminishing of the rhythm in egrl expression. Food reward together with food restriction caused a significant change in acrophase in per2 and npas2 rhythmic expression in the liver (cosinor, Table 2).

The most pronounced changes in response to food reward were observed in the PFC. Food reward caused a decrease in the amplitude of the per 2 daily profile, increased the mesor of egrl rhythm, caused a significant change in acrophase in the rev-erba daily profile and induced rhythm in npas 2 expression (Fig 1B, Fig. 2, cosinor, Table 2).

\section{Discussion}

Gene expression profiling revealed that DNAbinding transcriptional factor with zinc finger egrl (early growth response protein 1) and bHLH-PAS transcription factor npas2 can be involved in food reward-induced effects. Food reward provided during a passive phase of the LD cycle strongly influenced the expression of egr 1 and npas 2 predominantly in the PFC and DMH. The most interesting finding is the induction of npas 2 daily rhythm in the PFC in rewarded animals.

The provision of a food reward during the light time did not disrupt per2 rhythmic expression in any tissue. We observed an increase in the goodness of fit of the rhythm in per 2 expression in the SCN and glycemia. Rhythm in locomotor activity showed high levels during the dark time. These findings imply that the circadian system used food reward to support the dominant synchronizing signal, which in this case is the LD cycle. As expected, food reward together with food restriction caused a huge change in acrophase in gene expression in the liver, which is not observed after treatment with food reward alone. 
Table 2. Daily pattern of mRNA expression and glycemia in control and rewarded rats analyzed by cosinor analysis.

\begin{tabular}{|c|c|c|c|c|c|c|c|c|c|c|c|}
\hline & & & $\begin{array}{c}\text { Acrophase } \\
\text { (h:mm) }\end{array}$ & $\begin{array}{c}\text { Acrophase } \\
\text { SEM (h:mm) }\end{array}$ & & $\begin{array}{l}\text { Amplitude } \\
\text { (a.i.) }\end{array}$ & $\begin{array}{l}\text { Amplitude } \\
\text { SEM (a.i.) }\end{array}$ & $\begin{array}{l}\text { Mesor } \\
\text { (a.i.) }\end{array}$ & $\begin{array}{c}\text { Mesor } \\
\text { SEM (a.i.) }\end{array}$ & $\begin{array}{c}\text { Goodness } \\
\text { of fit }\end{array}$ & $\mathbf{P}$ \\
\hline \multirow{6}{*}{ DMH } & \multirow{2}{*}{ per 2} & control & $16: 37$ & $00: 56$ & & 0.313 & 0.066 & 1.22 & 0.051 & 0.652 & 0.000 \\
\hline & & reward & $14: 54$ & $00: 47$ & & 0.392 & 0.070 & 1.16 & 0.054 & 0.715 & 0.000 \\
\hline & \multirow{2}{*}{ egrl } & control & 06:26 & 00:59 & & 0.330 & 0.082 & 0.90 & 0.060 & 0.590 & 0.001 \\
\hline & & reward & ns & ns & & ns & $\mathrm{ns}$ & ns & ns & 0.393 & 0.080 \\
\hline & \multirow[b]{2}{*}{ npas 2} & control & 01:05 & 01:28 & & 0.235 & 0.090 & 1.21 & 0.064 & 0.432 & 0.041 \\
\hline & & reward & ns & $\mathrm{ns}$ & & ns & $\mathrm{ns}$ & ns & $\mathrm{ns}$ & 0.411 & 0.063 \\
\hline \multirow{6}{*}{ SCN } & \multirow{2}{*}{ per 2} & control & $10: 23$ & 01:08 & & 0.248 & 0.087 & 0.54 & 0.058 & 0.461 & 0.028 \\
\hline & & reward & 10:08 & $00: 34$ & & 0.269 & 0.048 & 0.49 & 0.032 & 0.709 & 0.000 \\
\hline & \multirow{2}{*}{ egrl } & control & 05:16 & 01:03 & & 0.622 & 0.153 & 1.37 & 0.117 & 0.598 & 0.001 \\
\hline & & reward & 06:16 & 01:24 & & 0.372 & 0.129 & 1.36 & 0.095 & 0.466 & 0.023 \\
\hline & \multirow{2}{*}{ npas 2} & control & 18:58 & 00:55 & & 1.126 & 0.268 & 3.70 & 0.192 & 0.608 & 0.001 \\
\hline & & reward & 19:00 & $00: 54$ & & 0.980 & 0.230 & 3.56 & 0.164 & 0.614 & 0.001 \\
\hline \multirow{6}{*}{ ARC } & \multirow{2}{*}{ per 2} & control & $15: 25$ & 00:54 & & 0.260 & 0.052 & 0.79 & 0.041 & 0.669 & 0.000 \\
\hline & & reward & $15: 00$ & $00: 56$ & & 0.262 & 0.055 & 0.86 & 0.043 & 0.652 & 0.000 \\
\hline & \multirow{2}{*}{$e g r l$} & control & ns & $\mathrm{ns}$ & & ns & $\mathrm{ns}$ & ns & $\mathrm{ns}$ & 0.330 & 0.168 \\
\hline & & reward & ns & $\mathrm{ns}$ & & ns & $\mathrm{ns}$ & ns & $\mathrm{ns}$ & 0.327 & 0.173 \\
\hline & \multirow{2}{*}{ npas 2} & control & 23:54 & $1: 16$ & & 0.119 & 0.043 & 0.77 & 0.029 & 0.448 & 0.031 \\
\hline & & reward & 00:40 & $1: 24$ & & 0.145 & 0.055 & 0.82 & 0.039 & 0.434 & 0.039 \\
\hline \multirow{8}{*}{ PFC } & \multirow{2}{*}{ per 2} & control & $15: 18$ & $00: 30$ & & 0.064 & 0.007 & 0.13 & 0.006 & 0.850 & 0.000 \\
\hline & & reward & $15: 45$ & 00:30 & & 0.050 & 0.006 & * 0.13 & 0.004 & 0.852 & 0.000 \\
\hline & \multirow{2}{*}{ egrl } & control & $17: 59$ & $00: 32$ & & 0.289 & 0.037 & 0.60 & 0.028 & 0.822 & 0.000 \\
\hline & & reward & 18:00 & 00:39 & & 0.292 & 0.047 & 0.68 & 0.035 & 0.751 & 0.000 \\
\hline & \multirow{2}{*}{ npas 2} & control & ns & $\mathrm{ns}$ & & ns & $\mathrm{ns}$ & ns & $\mathrm{ns}$ & 0.140 & 0.737 \\
\hline & & reward & 01:34 & 01:34 & & 0.102 & 0.040 & 0.57 & 0.029 & 0.421 & 0.048 \\
\hline & \multirow{2}{*}{ rev-erba } & control & 09:53 & $00: 23$ & & 0.638 & 0.076 & 1.22 & 0.050 & 0.833 & 0.000 \\
\hline & & reward & 09:03 & $00: 23$ & $*$ & 0.713 & 0.084 & 1.27 & 0.056 & 0.836 & 0.000 \\
\hline \multirow{10}{*}{ Liver } & \multirow{2}{*}{ per 2} & control & $16: 44$ & 00:21 & & 0.463 & 0.038 & 0.60 & 0.029 & 0.911 & 0.000 \\
\hline & & reward & $16: 31$ & $00: 16$ & & 0.478 & 0.029 & 0.60 & 0.023 & 0.947 & 0.000 \\
\hline & \multirow{2}{*}{ egrl } & control & $10: 34$ & 01:19 & & 0.161 & 0.065 & 0.37 & 0.043 & 0.412 & 0.061 \\
\hline & & reward & ns & $\mathrm{ns}$ & & ns & $\mathrm{ns}$ & ns & $\mathrm{ns}$ & 0.129 & 0.770 \\
\hline & \multirow{2}{*}{ npas 2} & control & 03:51 & $00: 22$ & & 0.527 & 0.043 & 0.41 & 0.033 & 0.911 & 0.000 \\
\hline & & reward & 03:54 & 00:23 & & 0.563 & 0.050 & 0.41 & 0.039 & 0.898 & 0.000 \\
\hline & \multirow{2}{*}{ per 2} & control & $16: 50$ & $00: 34$ & & 2.068 & 0.302 & 2.32 & 0.214 & 0.870 & 0.000 \\
\hline & & restriction & 05:00 & 00:46 & $*$ & 1.438 & 0.288 & * 1.86 & 0.204 & 0.736 & 0.000 \\
\hline & \multirow{2}{*}{ npas 2} & control & 01:10 & $00: 36$ & & 0.249 & 0.039 & 0.20 & 0.027 & 0.857 & 0.000 \\
\hline & & restriction & $14: 28$ & $00: 48$ & * & 0.313 & 0.066 & 0.21 & 0.047 & 0.719 & 0.001 \\
\hline \multirow{2}{*}{ Plasma } & glucose & control & ns & $\mathrm{ns}$ & & ns & ns & ns & $\mathrm{ns}$ & 0.347 & 0.137 \\
\hline & & reward & $17: 47$ & $01: 26$ & & 1.566 & 0.532 & 10.62 & 0.402 & 0.470 & 0.021 \\
\hline
\end{tabular}

Mesor - average value of fitted curve; Amplitude - value of curve peak relative to mesor; Acrophase - time of curve peak from circadian time zero (dark-to-light transition) in hour:minutes. Mesor and amplitude are given in relative units (a.i.). Amplitude is given in hour:minutes (h:mm). ns - nonsignificant daily change. SCN - suprachiasmatic, ARC - arcuate, DMH - dorsomedial nuclei, PFC - prefrontal cortex. * $\mathrm{P}<0.05$, cosinor. 

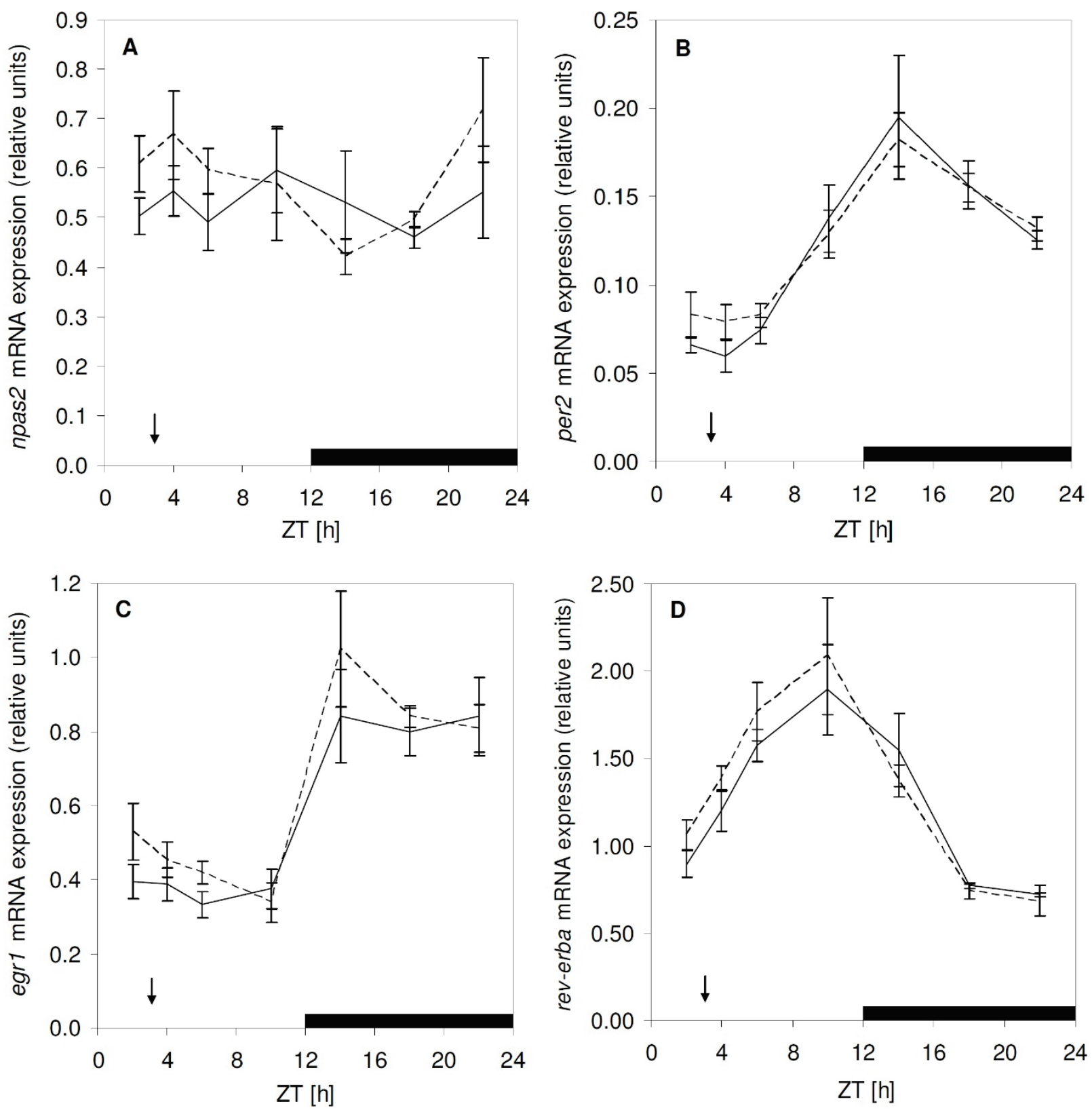

Fig. 2. Daily profile of npas2 (A), per2 (B), egr1 (C) and rev-erba (D) in the prefrontal cortex of control rats (solid line) and rats provided with food rewards over 16 days at ZT3 (broken line). The rats were exposed to a 12:12 LD cycle. The black arrows indicate food reward delivery. The black bars at the bottom of the charts indicate the dark part of the LD cycle.

The effect of food reward on clock gene expression during a $24 \mathrm{~h}$ cycle was studied predominantly in the limbic system and brain regions involved in energy homeostatic regulation (Verwey et al. 2007, Verwey et al. 2008, Mendoza et al. 2010, Challet and Mendoza 2010). In our study, the expression of per 2 showed a distinct daily rhythm as in the DMH of rats (Monošíková et al. 2007, Minana-Solis et al. 2009) and mice (Moriya et al. 2009) with the same acrophase as it was reported earlier. It is well known that food restriction strongly amplifies per expression and the amplitude of its rhythm in the DMH (Verwey et al. 2007, Moriya et al.
2009, Verwey et al. 2008). Compared to this effect, the change in per 2 expression after food reward is much less pronounced in this structure.

There was a distinct daily pattern in egrl and npas 2 expression in the $\mathrm{DMH}$ in the control group. Food reward caused an increase in egr 1 and npas 2 expression $1 \mathrm{~h}$ after reward delivery that led to rhythm diminishing. This finding implies that the $\mathrm{DMH}$, which is involved in the regulation of wakefulness and responsiveness to environmental cues that are important to the animal, can facilitate food reward acceptance at the right time.

Food reward did not induce change either in the 
per2 daily pattern as reported earlier (Moriya et al. 2009) or in egr 1 and npas 2 expression in the ARC.

We observed a pronounced daily rhythm in per 2 , npas 2 and egr 1 expression in the liver with the maximum as was reported before (Damiola et al. 2000, Tao et al. 2015). per 2 and npas 2 expression was not influenced by food reward; however, food reward caused a diminishing of egrl rhythmic expression. Food reward with food restriction caused a pronounced phase shift in gene expression as was reported earlier (Damiola et al. 2000, Tao et al. 2015).

The PFC, which receives input from the mesolimbic system, is involved in executive behavioral response and influences behavioral strategy preservation (Reick et al. 2001, Dudley et al. 2003). The induction of npas 2 rhythm is most probably related to one of these PFC functions, allowing animals to accept food reward during a passive phase without major disturbance of the rhythm in locomotor activity. The rhythmic pattern of egrl in the PFC showed increased mesor in rewarded animals. The expression of rev-erba showed a significant change in acrophase and trend to increased amplitude. rev-erba has lately proved to be crucial for food restriction-induced behavior. Since npas 2 contains the binding domain for rev-erba it is possible that change in rev-erba expression contributed to the changed pattern in npas 2 expression (Delezie et al. 2016).

Unlike the DMH, changes in egr1 and npas2 expression in the PFC do not show an acute response at the time of food reward delivery. Changes observed in gene expression influenced the daily pattern.

While npas 2 is known for its role in the circadian oscillator function, egrl is known mainly as an immediate early gene involved in neural development, cell differentiation, memory and learning (Beckmann and Wilce 1997). Its direct connection to the circadian system was recently established when functional E-box was identified in its sequence (Tao et al. 2015). In spite of the presence of functional E-box, egrl shows surprising variability in its acrophase in tissues with similar expression of the BMAL1 (NPAS2)/CLOCK heterodimer. This variability implies more complex egr 1 regulation, which is supported by the presence of a variety of response elements in the egrl promoter (Meyer et al. 2002).

The PFC is known to play a role in reward response (Warren et al. 2016) after activation of the mesolimbic system (Webb et al. 2015). Changes in gene expression in the DMH could be induced by input from the lateral hypothalamus, which is in addition to the regulation of food behavior also involved in the regulation of sleep and wakefulness, food reward responsiveness, addiction and energy homeostasis (Feillet et al. 2015). These functions are regulated via afferentation from the limbic system and by humoral satiety signals, metabolic cues and glucose from the periphery (Sakurai et al. 2007). In both cases a possible link between changed genes expression and exact mechanism of molecular signaling leading to changed behavior needs to be elucidated.

To conclude, food reward of low hedonic and caloric value provided during a passive phase of the LD cycle induced npas 2 rhythm in the PFC and increased npas 2 and egr 1 expression in the DMH. The DMH can influence the SCN to modulate the pattern of wakefulness and the PFC most probably contributes to executive behavior during reward presentation. We observed an improved rhythmicity in per2 expression in the SCN and plasma glucose levels. These findings imply that regularly administered food rewards of small hedonic and caloric value can reinforce entrainment of the circadian system to the actual LD cycle even if the reward is presented in a passive phase of the LD cycle.

\section{Conflict of Interest}

There is no conflict of interest.

\section{Acknowledgements}

Supported by grants: VEGA 1/0499/15, APVV-0291-12.

\section{References}

BECKMANN AM, WILCE PA: Egr transcription factors in the nervous system. Neurochem Int 31: 477-510, 1997.

CHALLET E, MENDOZA J: Metabolic and reward feeding synchronises the rhythmic brain. Cell Tissue Res 341: 1-11, 2010.

DAMIOLA F, LE MINH N, PREITNER N, KORNMANN B, FLEURY-OLELA F, SCHIBLER U: Restricted feeding uncouples circadian oscillators in peripheral tissues from the central pacemaker in the suprachiasmatic nucleus. Genes Dev 14: 2950-2961, 2000. 
DELEZIE J, DUMONT S, SANDU C, REIBEL S, PEVET P, CHALLET E: Rev-erb $\alpha$ in the brain is essential for circadian food entrainment. Sci Rep 6: 29386, 2016.

DUDLEY CA, ERBEL-SIELER C, ESTILL SJ, REICK M, FRANKEN P, PITTS S, MCKNIGHT SL: Altered patterns of sleep and behavioral adaptability in NPAS2-deficient mice. Science 301: 379-383, 2003.

FEILLET CA, BAINIER C, MATEO M, BLANCAS-VELÁZQUEZ A, SALABERRY NL, RIPPERGER JA, ALBRECHT U, MENDOZA J: Rev-erb $\alpha$ modulates the hypothalamic orexinergic system to influence pleasurable feeding behaviour in mice. Addict Biol 22: 411-422, 2017.

HERICHOVÁ I, ŠOLTÉSOVÁ D, SZÁNTÓOVÁ K, MRAVEC B, NEUPAUEROVÁ D, VESELÁ A, ZEMAN M: Effect of angiotensin II on rhythmic per2 expression in the suprachiasmatic nucleus and heart and daily rhythm of activity in Wistar rats. Regul Pept 186: 49-56, 2013.

KO CH, TAKAHASHI JS: Molecular components of the mammalian circadian clock. Hum Mol Genet 15: R271-R277, 2006.

LENARD NR, BERTHOUD HR: Central and peripheral regulation of food intake and physical activity: pathways and genes. Obesity (Silver Spring) 16 (Suppl 3): S11-S22, 2008.

MINANA-SOLIS MC, ANGELES-CASTELLANOS M, FEILLET C, PEVET P, CHALLET E, ESCOBAR C: Differential effects of a restricted feeding schedule on clock-gene expression in the hypothalamus of the rat. Chronobiol Int 26: 808-820, 2009.

MENDOZA J, CLESSE D, PÉVET P, CHALLET E: Food-reward signalling in the suprachiasmatic clock. J Neurochem 112: 1489-1499, 2010.

MEYER RG, KÜPPER JH, KANDOLF R, RODEMANN HP: Early growth response-1 gene (Egr-1) promoter induction by ionizing radiation in U87 malignant glioma cells in vitro. Eur J Biochem 269: 337-346, 2002.

MONOSÍKOVÁ J, HERICHOVÁ I, MRAVEC B, KISS A, ZEMAN M: Effect of upregulated renin-angiotensin system on per2 and bmal1 gene expression in brain structures involved in blood pressure control in TGR(mREN-2)27 rats. Brain Res 1180: 29-38, 2007.

MORIN LP: Neuroanatomy of the extended circadian rhythm system. Exp Neurol 243: 4-20, 2013.

MORIYA T, AIDA R, KUDO T, AKIYAMA M, DOI M, HAYASAKA N, NAKAHATA N, MISTLBERGER R, OKAMURA H, SHIBATA S: The dorsomedial hypothalamic nucleus is not necessary for food-anticipatory circadian rhythms of behavior, temperature or clock gene expression in mice. Eur J Neurosci 29: 1447-1460, 2009.

REICK M, GARCIA JA, DUDLEY C, MCKNIGHT SL: NPAS2: an analog of clock operative in the mammalian forebrain. Science 293: 506-509, 2001.

SAKURAI T: The neural circuit of orexin (hypocretin): maintaining sleep and wakefulness. Nat Rev Neurosci 8: 171-181, 2007.

SCHWARTZ JR, ROTH T: Neurophysiology of sleep and wakefulness: basic science and clinical implications. Curr Neuropharmacol 6: 367-378, 2008.

SKENE DJ, ARENDT J: Human circadian rhythms: physiological and therapeutic relevance of light and melatonin. Ann Clin Biochem 43: 344-353, 2006.

TAHARA Y, SHIBATA S: Chronobiology and nutrition. Neuroscience 253: 78-88, 2013.

TAO W, WU J, ZHANG Q, LAI SS, JIANG S, JIANG C, XU Y, XUE B, DU J, LI CJ: EGR1 regulates hepatic clock gene amplitude by activating Per1 transcription. Sci Rep 5: 15212, 2015.

WARREN BL, MENDOZA MP, CRUZ FC, LEAO RM, CAPRIOLI D, RUBIO FJ, WHITAKER LR, MCPHERSON KB, BOSSERT JM, SHAHAM Y, HOPE BT: Distinct Fos-expressing neuronal ensembles in the ventromedial prefrontal cortex mediate food reward and extinction memories. Neurosci 36: 6691-6703, 2016.

VERWEY M, KHOJA Z, STEWART J, AMIR S: Differential regulation of the expression of Period2 protein in the limbic forebrain and dorsomedial hypothalamus by daily limited access to highly palatable food in food-deprived and free-fed rats. Neuroscience 147: 277-285, 2007.

VERWEY M, KHOJA Z, STEWART J, AMIR S: Region-specific modulation of PER2 expression in the limbic forebrain and hypothalamus by nighttime restricted feeding in rats. Neurosci Lett 440: 54-58, 2008. 
WEBB IC, LEHMAN MN, COOLEN LM: Diurnal and circadian regulation of reward-related neurophysiology and behavior. Physiol Behav 143: 58-69, 2015. 